\title{
Understanding citation patterns between impact-factor and blacklisted journals*
}

\author{
Emanuel Kulczycki ${ }^{1 *}$, Marek Hołowiecki $^{1}$, Zehra Taşkın $^{1}$, Franciszek Krawczyk ${ }^{1}$ \\ ${ }^{l}$ Scholarly Communication Research Group, Adam Mickiewicz University in Poznań (Poland) \\ *emek@amu.edu.pl
}

\author{
ORCIDs: \\ Emanuel Kulczycki: 0000-0001-6530-3609 \\ Marek Hołowiecki: 0000-0001-8217-2815 \\ Zehra Taşkın: 0000-0001-7102-493X \\ Franciszek Krawczyk: 0000-0003-1097-9032
}

\begin{abstract}
One of the most fundamental issues in academia today is understanding the differences between legitimate and predatory publishing. While decision-makers and managers consider journals indexed in popular citation indexes such as Web of Science or Scopus as legitimate, they use two blacklists (Beall's and Cabell's), one of which has not been updated for a few years, to identify predatory journals. The main aim of our study is to reveal the contribution of the journals accepted as legitimate by the authorities to the visibility of blacklisted journals. For this purpose, 65 blacklisted journals in social sciences and 2,338 Web-of-Science-indexed journals that cited these blacklisted journals were examined in-depth in terms of index coverages, subject categories, impact factors and self-citation patterns. We have analysed 3,234 unique cited papers from blacklisted journals and 5,964 unique citing papers $(6,750$ citations of cited papers) from Web of Science journals. We found that $13 \%$ of the blacklisted papers were cited by WoS journals and $37 \%$ of the citations were from impact-factor journals. As a result, although the impact factor is used by decision-makers to determine the levels of the journals, it has been revealed that there is no significant relationship between the impact factor and the number of citations to blacklisted journals. On the other hand, country and author self-citation practices of the journals should be considered. All the findings of this study underline the importance of the second part of this study, which will examine the contents of citations to articles published in predatory journals because understanding the motivations of the authors who cited blacklisted journals is important to correctly understand the citation patterns between impact-factor and blacklisted journals.
\end{abstract}

Keywords: blacklisted journals; Beall's list; Cabell's list; citation analysis, citation patterns

\section{Funding}

The work was financially supported by the National Science Centre in Poland (Grant Number UMO-2017/26/E/HS2/00019).

\section{Acknowledgments}

The authors would like to thank Ewa A. Rozkosz for her support. Part of the initial result of this study has been submitted to ISSI 2021 conference as a 'Research in progress' paper.

\section{Introduction}

Journals as a key communication channel in science receive much attention from scholars, editors, policymakers, stakeholders and research-evaluation bodies because journals are used as a proxy of the research quality of the papers published in them. Publishing in top-tier journals is perceived as the mark of the researcher's quality and productivity. In today's science, the best journals that make the research results and papers visible are mostly defined by their

\footnotetext{
${ }^{*}$ This is the pre-print version of a submitted article.
} 
Journal Impact Factor (JIF) (Else, 2019), despite the many cases of its abuse. Impact-factor journals are perceived as journals that are legitimated by experts in a given field; thus, papers cited by such journals are also valorised more, even though there might be various motivations behind the citations in question (Leydesdorff et al., 2016).

While the impact factor is often used to identify quality publications in the scientific community, low-quality publications and ethical issues in publishing have recently been discussed. Predatory publishing is one of the most discussed topics regarding journal publishing, which crosses over narrow fields of bibliometrics, scientometrics and academicpublishing studies. This topic related to publishing in so-called questionable or low-quality journals attracts attention not only in academia but also outside it (Bohannon, 2013; Sorokowski et al., 2017). Predatory journals, accused of damaging science and diminishing the quality of scholarly communication and trust in science, are trying to be classified and listed. In recent years, the most famous attempt to list predatory journals was initiated by Jeffrey Beall, whose list (henceforth: Beall's list) gained attention from scientific fields and media. The second wellknown approach is done by the company Cabell's International (henceforth: Cabell's list), which not only lists predatory journals but also offers another product listing 'reputable' journals. Thus, journals listed on Beall's or Cabell's lists are called in this study blacklisted journals in contrast to whitelisted journals (listed in reputable international indexes like Scopus, Web of Science Core Collection [WoS] or the European Reference Index for the Humanities and Social Sciences).

Beall describes predatory journals as those ready to publish any article for payment and not following basic publishing standards, such as peer reviewing (Beall, 2013). The term 'predatory journals' produces tension because, as Krawczyk and Kulczycki (2020) show, from the beginning it accuses open publishing as the key source of predatory publishing. Beall has published long lists of criteria by which he has created his list of predatory journals. However, these criteria were accused of being too subjective, and the whole process of creating of the list was criticised as non-transparent (Olivarez et al., 2018). According to Siler (2020), Cabell's list was created more transparently, and each journal was evaluated by 78 well-defined indices of quality. Different violations can be assigned to each journal, from 'minor' like poor grammar on the journal website to 'severe' like false statements about being indexed in prestigious databases like WoS (Siler, 2020). Moreover, each blacklisted journal is described alongside its violations of good publishing practices (not the case in Beall's list) (Anderson, 2017). The main disadvantage of Cabell's list is that access to it requires expensive subscriptions, so many scholars are unable to use it.

This study is the first extensive study looking at citations from WoS-indexed journals to papers published in blacklisted (or predatory) journals. Demir (2018a) pointed out a big difference between the largest citation databases: Scopus indexes 53 predatory journals from Beall's lists, but WoS indexes only three such journals and Somoza-Fernández et al. (2016) reported that this difference is smaller but still visible. This could also suggest a difference in citations to predatory journals in these databases, but previous attempts at analysing such citations were based mostly on Google Scholar data (due to an easier data-acquisition procedure) or Scopus. Björk et al. (2020) analysed Google Scholar citations of 250 articles from predatory journals. Nwagwu and Ojemeni (2015) analysed 32 biomedical journals published by two Nigerian publishers listed on Beall's list. Bagues et al. (2019) investigated how journals listed in Beall's list (in which Italian researchers published their works) are cited in Google Scholar. Oermann et al. (2019) analysed Scopus citations of seven predatory nursing journals. Moussa (2020), using Google Scholar, examined citations of 10 predatory marketing journals. Frandsen (2017) 
analysed how 124 potential predatory journals are cited in Scopus. Anderson (2019) in a blog post showed how seven predatory journals were cited in WoS, the ScienceDirect database and PLoS One. Our study provides the results of the analysis of 3,234 unique cited papers from 65 blacklisted journals and 5,964 unique citing papers (6,750 citations of cited papers) from 2,338 WoS journals (of which 1,047 are impact-factor journals).

The number of citations to the articles in predatory journals varies depending on the methodology used in the study. By using Scopus, Frandsen (2017) found 1,295 citations to 125 predatory journals and Oermann et al. (2019) found 814 citations to seven predatory nursing journals that had published at least 100 papers each. When Google Scholar was used to analyse predatory journals, the number of citations to these journals was higher. Björk et al. (2020) found that articles in predatory journals receive on average 2.6 citations per article and $43 \%$ of articles are cited. Nwagwu and Ojemeni (2015) reported an average of 2.25 citations per article in a predatory journal. In contrast to other research, Moussa (2020) argues that predatory journals in marketing have a relatively high number of citations in Google Scholar, with an average of 8.8 citations per article.

However, even if we agree with all the aforementioned studies that papers in predatory journals have received much fewer citations than, for example, papers indexed in WoS, then the number of citations in legitimate journals to potentially non-peer-reviewed articles can still be substantial. Shen and Björk (2015) estimated that there were around 8,000 active journals listed by Beall or published by publishers listed by him, and those journals published 420,000 articles in 2014. Demir (2018b) found 24,840 papers published in 2017 in 832 journals indexed in Bell's blacklist of journals. At the moment, Cabell's Predatory Report indexes 14,664 journals (Cabells, 2021).

Although Frandsen (2017) argues that authors of predatory journals are mostly inexperienced researchers (i.e., those who have published less-than-average articles in Scopus) from peripheral countries, Oermann et al. (2019) presented that citing authors were most frequently affiliated, accordingly, to the USA, Australia and Sweden. Oermann et al. (2020) studied further articles in which predatory journals are cited and found that most of the citations are used substantively and placed in the introduction or literature review sections. Moreover, by analysing a small sample of the best-cited articles from predatory journals, Moussa (2020) found that around $10 \%$ of citing articles from Google Scholar were published in journals indexed in the Social Sciences Citation Index, and Oermann et al. (2019) did not find any significant difference in citations in Scopus from impact-factor and non-impact-factor nursing journals.

Citations provide vital connections between scientific studies to spread knowledge and drive further research (Oppenheim, 1996, p. 155). Authors cite others to support, discuss or compare their research to others. However, after using the number of citations as data for research evaluations, the meanings and purposes of citations have widened and serve also for the assessment and evaluation. The success of authors, institutions, journals or countries has been evaluated using the metrics calculated by the number of publications and citations.

Frauds in science are not limited to publishing predatory or questionable journals because gaming with only the number of publications is not enough to change the metrics. Individuals or organisations that have discovered the relevance of numerical success in science and visibility have started citation-manipulation games in addition to publishing predatory journals because visibility provides citation advantages. If the paper has been cited at least once, it is 
likely to be cited again (Simkin \& Roychowdhury, 2015). In the literature, there have been many papers published to show the authors and editors how to maximise the research visibility and citations in an ethical way (e.g. Norman, 2012, 2013) because it is believed that the more citations, the more prestige.

However, this creates new types of manipulation. Some authors and journals use self-citations as a visibility strategy because the first self-citations play an important role in the citation of the work by increasing visibility (González-Sala et al., 2019). Coercive citations requested by editors or reviewers, excessive self-citations and citation-stacking issues make all the metrics meaningless because it is easy to play with them.

To avoid these kinds of problems, a new concept has emerged in the information-science field called content-based citation analyses, which focusses on the contents of the citations, not the numbers. It is possible to understand and classify the citations in terms of meanings, purposes, arrays and shapes with the help of these analyses (Taşkın \& Al, 2018). This also provides the opportunity to understand the citation motivations of authors and the effects of the publish-orperish culture on their motivations.

In this paper, we analyse citations from indexes that are commonly accepted as 'legitimate' to journals blacklisted as predatory, but we do not evaluate the quality or questionable behaviours of the journals. Although one can observe some common trends in defining predatory journals (Krawczyk \& Kulczycki, 2020), there is no agreed definition or common-sense method of distinguishing predatory journals from non-predatory ones (Cobey et al., 2018). Partly as a critique of the whole concept of predatory publishing, Stöckelová and Vostal (2017) point out that instead of focussing on publishers, scholars should criticise the whole system of globalmodern scholarly communication. This is the tension between profit and non-profit journals or the academic north and south that enables operations of predatory journals and not only the bad will of some publishers.

Moreover, Beall was accused of being prejudiced against journals from foreign countries (Houghton, 2017) and open access (Bivens-Tatum, 2014), and these prejudices may have influenced the list he was creating. Also, Siler (2020) noticed that most of the journals are not black or white but grey - they are not fully illegitimate but they perform some questionable activities - and as such, questionable activity can also be seen in the high prices of journals set by the biggest publishers like Springer or Elsevier. However, there is no doubt that journals listed as predatory are heavily criticised. Our study will focus on the conflict between tools to reveal the illegitimate nature of a journal (Beall's and Cabell's blacklists) and citations in a prestigious citation database $(\mathrm{WoS})$, which is often seen as a source of scholarly legitimisation.

In this paper, we provide a systematic citation study focussing on journals covered by WoS products and on citers in terms of their country affiliation and self-citation practices. The study aim is two-fold: the first is to analyse the visibility of blacklisted journals, and the second is to understand citation contexts. This paper is the first paper of a bigger endeavour aiming to investigate how papers published in blacklisted journals from the field of social sciences are cited by papers published by journals indexed in the WoS. This paper will be followed by an upcoming study on the content-based analysis of citations of the blacklisted papers to evaluate the citations in terms of their content (meaning, purpose, shape, array). This is the key reason why we focus on social-sciences journals here: evaluating the content of citations will require expertise in the field (Cano, 1989). 


\section{Data and Methods}

\section{Data sources}

We have used two blacklists: Beall's and Cabell's lists. Moreover, we have collected journals' ISSNs from their websites and used the ISSN Portal to find variants of journal titles and ISSNs as well as provide data of the country of publishing. The data on citations of papers published in selected journals were obtained from the WoS using the Cited Reference Search. We focussed on three main WOS products: Journal Citation Reports (JCR) based on the Science Citation Index Expanded and the Social Sciences Citation Index, the Arts and Humanities Citation Index (A\&HCI), and the Emerging Sources Citation Index (ESCI). We downloaded PDF files of either paper from blacklisted journals and WoS-indexed journals to collect and verify the country affiliations of the authors. Using the blacklisted journal websites, we collected the data on the number of papers published by each journal.

\section{Selecting blacklisted journals}

We have used two blacklists of journals, Beall's blacklist of standalone predatory journals and Cabell's list, to select social-sciences journals for our analysis. The first one consisted of 1,310 standalone journals, but we found that some of them were duplicates. The list was updated for the last time on 9 January 2017 and then was removed from Beall's website. We have used the Wayback Machine (http://web.archive.org) to obtain this last version. The other one, Cabell's list, might be perceived as a successor of Beall's list. In January 2019, Cabell's blacklist consisted of 10,496 journals. We have decided to include in the analysis only active journals, which have been defined as journals that published at least one paper in each year of the 20122018 period, and their websites were active at the moment of the start of this study (May 2019).

The selection of journals was conducted in three steps. In the first step, we started from the analysis of Beall's list, as it was the very first attempt to blacklist journals and the key source for the discussion on predatory publishing. We found that 322 unique journals (24.6\%) of 1,310 journals from Beall's list were active at the moment of our analysis. Based on expert decisions, two authors of this study classified journals according to the fields of science across seven groups: (1) Humanities [H], (2) Social Sciences [SS], (3) Hard Science [Hard], (4) Multidisciplinary 1 [scope covers H, SS, Hard], (5) Multidisciplinary 2 [scope covers SS, Hard], (6) Multidisciplinary 3 [scope covers H, SS] and (7) Multidisciplinary 4 [scope covers H, Hard]. We classified journals according to their titles, aims and scopes published on journals' websites. The points of reference for assigning a particular journal to one of seven categories were the fields of science and technology in the Organisation for Economic Co-operation and Development (2007). Finally, we decided to merge all multidisciplinary journals into a single category because the boundaries between some of them were blurry.

Therefore, in this study, a multidisciplinary journal is defined as a journal that publishes in at least two of three main fields, i.e., Humanities, Social Sciences and Hard Sciences. The number of active journals from Beall's list $(N=322)$ across four fields is as follows: Hard Sciences (203), Humanities (2), Multidisciplinary (78) and Social Sciences (39). We have decided to exclude from the analysis journals that were indexed in WoS even if only for one year in at least one of three selected WoS products during the years 2012-2018 $(N=34,10.6 \%)$. The reason for this is to focus strictly on journals that were never legitimised by indexing in WoS. Moreover, citations from journals not indexed in WoS could not serve to play with the citation numbers and increase 
the impact-factor value of other journals. To prepare the final sample, we excluded two journals that were indexed in $\mathrm{WoS}$ and included all other active journals from the social sciences $(N=37)$.

In the second step of the selection of journals, we decided to include 37 social-sciences journals from Cabell's list. The journals were assigned to the fields of sciences by their titles to provide complementary additions to the initial sample of social-sciences journals. Journals' websites were checked to confirm that every single journal meets the activeness criteria. Journals from Cabell's list were also checked in the ISSN Portal (variants of titles and ISSNs) as well as in the WoS (whether they were indexed in this database). All of those that were selected for the sample were never indexed in the WoS.

In the final step, journals selected from Beall's list were manually searched in Cabell's list. The same procedure was repeated for selected journals from Cabell's list, and we investigated whether they were in Beall's list or not. In the sample, we have 74 unique journals. However, there is a subset of 10 overlapping journals that are listed on both lists.

\section{Cited and citing papers}

We prepared two datasets. The first one consists of the bibliographic data and PDF files of the papers published in the years of 2012-2018 in the social-sciences blacklisted journals included in this study and were cited by journals indexed in WoS (henceforth: cited papers). The other dataset consists of data on the papers (i.e., all journal publication types) published in journals indexed in WoS in the years 2012-2019 (henceforth: citing papers) that cited papers from the first dataset.

The following steps have allowed us to collect the data for both datasets. First, we used the Cited Reference Search to search the cited references of WoS-indexed papers, in which authors referred to papers published in the analysed journals, which are sources not indexed in WoS. We took the titles of analysed journals and prepared search queries with all gathered versions of titles for each journal. We found 4,968 bibliographical records that were published by 71 blacklisted journals. Papers from three analysed blacklisted social-science journals have never been cited in the analysed period.

Secondly, we identified duplicated records of cited papers and merged them. After the removal of the duplicates, we obtained the dataset consisting of 4,615 unique cited papers from 71 blacklisted journals and 8,276 unique citing papers from 3,347 WoS-indexed journals. In the next step, PDF files of cited papers were downloaded. Of the 4,615 cited papers, 1,204 (26\%) were not able to be downloaded. The main reasons were (1) missing files on the journals' website, (2) no information about a paper on a journal website and (3) an archive on a journal website was inactive. We collected data on the affiliation of the corresponding authors of each cited paper from PDF files, where the corresponding author was explicitly indicated. If the corresponding author was not indicated, the affiliation of the first author was gathered. If the corresponding first author had more than one country of affiliation, then the first affiliation was gathered. In a further analysis, we included 3,234 cited papers from 65 blacklisted journals that have the PDF files downloaded, were cited at least once in the period 2012-2019 in journals indexed in WoS, and have information about the country affiliation of the corresponding author. To analyse what share of papers from a given journal has been cited in WoS, we also counted the number of all papers published in a given journal in the analysed period. 
Third, we collected the full records and bibliographic data from the WoS of all 8,276 citing papers. We collected the affiliation of corresponding authors from the information about 'Reprint Address' included in the WoS data (only the first 'Reprint Address' was counted). Having collected all affiliations, we extracted the names of countries. The names of countries of the cited papers' authors were unified to match the list of countries used in the WoS. We excluded all citing papers that (1) were not published in the period 2012-2019, (2) have a different publication type in WoS than 'Journal' or (3) whose PDF file of the paper we were unable to download using either our institutional-access or open-access repositories. In a further analysis, we included 5,964 citing papers.

Fourthly, we collected for each citing paper the information regarding whether a journal of a citing paper was included in the WoS product (JCR, AHCI, ESCI) in the year of the citing paper's publication. Finally, we analysed 3,234 unique cited papers from 65 blacklisted journals and 5,964 unique citing papers (6,750 citations of cited papers) from 2,338 WoS journals. The list of analysed blacklisted journals is in Appendix 1.

\section{Results}

\section{PART A: Blacklisted and Web-of-Science-listed journals}

\section{A.1. Share of cited papers from blacklisted journals}

Between 2012 and 2018, 65 analysed journals published 25,146 papers, of which 3,234 (13\%) were cited by WoS journals.

Figure 1. Share and Number of Cited Papers from Blacklisted Journals by WoS Journals

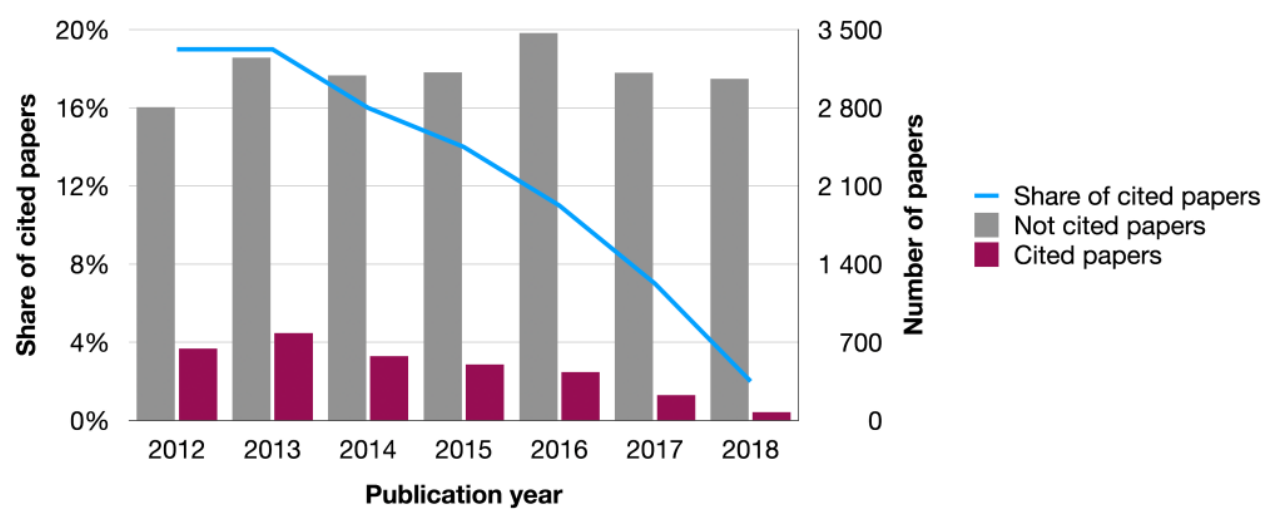

Figure 1 shows the highest share, 19\%, in 2012 and 2013. The mean number of papers published by a single journal in the analysed period was $53.5(\mathrm{~min}=43$, $\max =2,176)$. On average, $11 \%$ of papers published by a journal were cited by WoS journals. The highest shares were found for journals that published 1,748 and 259 papers. The shares are 36\% (635 papers) and 35\% (91 papers), respectively.

Table 1 shows the number and shares of cited papers according to blacklists. In the analysed sample, 8,327 papers were published in journals listed in Beall's list (10.3\% of them were cited) and 13,910 papers from journals indexed in Cabell's list (14.7\% were cited). 5,587 papers were published by journals indexed in both Beall's and Cabell's lists. 
Table 1. Number and Share of Cited Papers in Blacklisted Journals $(N=65)$ According to Blacklists

\begin{tabular}{lcccc}
\hline \multicolumn{1}{c}{ Blacklist } & $\begin{array}{c}\text { Number of } \\
\text { journals }\end{array}$ & $\begin{array}{c}\text { Number of all } \\
\text { papers }\end{array}$ & $\begin{array}{c}\text { Number of cited } \\
\text { papers }\end{array}$ & Share \\
\hline Beall's list & 22 & 8,327 & 860 & $10.3 \%$ \\
Beall \& Cabell's & 8 & 5,587 & 323 & $5.8 \%$ \\
lists & 35 & 13,910 & 2,051 & $14.7 \%$ \\
Cabell's list & &
\end{tabular}

We checked whether 65 analysed journals were covered by Scopus, as this could potentially influence the share of citations. We found that five of 65 were or have been covered: one has been covered by the whole analysed period ( $24 \%$ of papers were cited), one was removed from Scopus before the analysed period (23\%), one was covered and removed in the analysed period (36\% papers), one was covered in the last year of the analysed period (19\%) and one was covered before the analysed period and removed during the period $(8 \%)$.

\section{A.2. Web of Science journals citing blacklisted journals}

We found that 2,338 unique WoS journals cited 3,234 blacklisted papers 6,750 times. The number of citations per blacklisted journal from WoS journals is 2.88 (median $=1$, minimum=1, maximum=218). The mean number of papers from WoS journals that cited analysed blacklisted papers was 2.88. Half of the citations were from 261 journals. Eighty-nine of 2,338 journals cited at least 10 times papers from blacklisted journals, and four WoS journals cited over 100 blacklisted papers. In the analysed period, one WoS journal published 183 papers, which cited blacklisted papers from our sample 218 times (all except one published in one blacklisted journal). One of these blacklisted papers was cited 36 times by this WoS journal.

We analysed in which WoS product (JCR, ESCI, A\&HCI) a journal was indexed when a citing paper was published. We considered the publication year and whether a journal was included in the WoS product in the year in question. We found that 1,152 of 2,338 journals were indexed in ESCI, 35 in A\&HCI, and 1,047 in JCR. One-hundred and four journals that published 366 citing papers were neither in ESCI, A\&HCI nor in JCR, which means they were either in SCIE or SSCI indexes but not yet JCR (e.g., waiting for calculation of their impact factor) or dropped from the indexes because of quality issues or manipulations such as citation stacking or excessive self-citation rates. Figure 2 shows how blacklisted journals were cited by WoS journals. Of the 6,750 citations, 2,502 (37\%) were from JCR journals, 3,821 (56.6\%) were from ESCI journals and $61(0.9 \%)$ were from A\&HCI journals. 
Figure 2. WoS Journals Citing Blacklisted Journals According to Blacklists

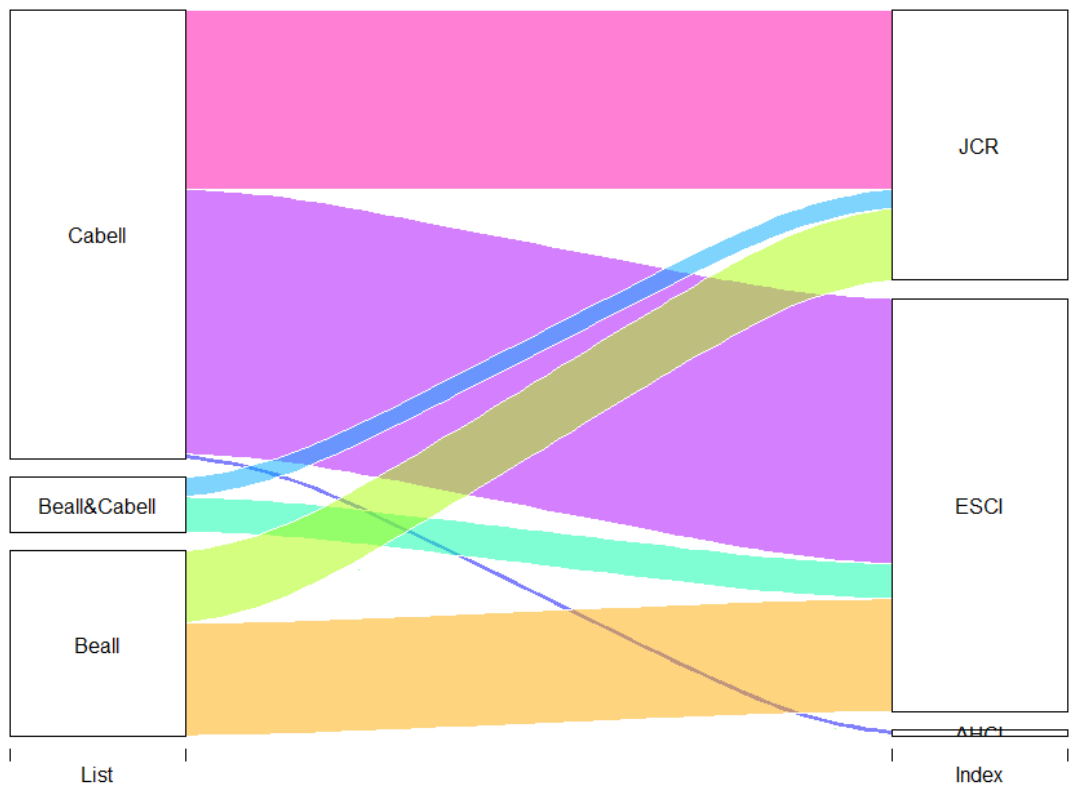

The blacklisted journals were selected only from social sciences; however, citations from all fields in WoS were considered for the evaluation of citations. The distribution of subjects to WoS subjects and broader OECD classifications (Clarivate Analytics, 2012) is shown in Figure 4. The results are important because they prove the existence of citations from different subjects (such as medical sciences and agriculture) to social-science papers appearing in blacklisted journals.

Figure 3. Distribution of Citing Journals to WoS Subject Categories and OECD Major Fields

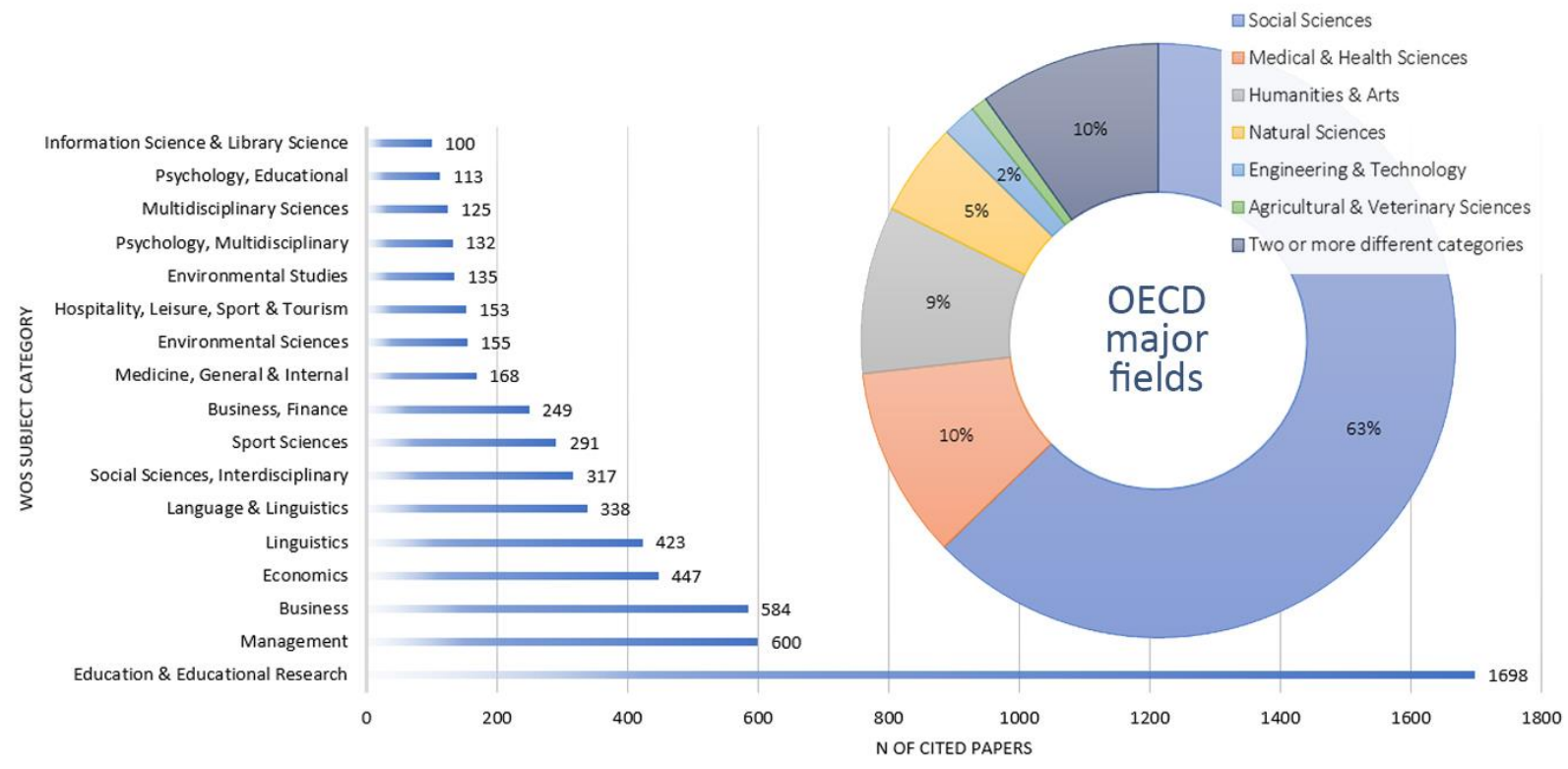

Figure 3 shows that $25 \%$ of WoS citations were from one field, Education and Educational Research. This is followed by Management (8.9\%) and Business (8.7\%). In total, $63 \%$ of journals were classified in Social Sciences. According to the WoS classification of journals, a journal may be classified into two or more different subject fields. Six-hundred and sixty-five 
papers in 256 journals in our dataset were classified into two or more different categories. The Kruskal-Wallis test results show that there are significant differences between the journals' OECD category and the number of citations to blacklisted journals $\left(\chi^{2}=75.641, \mathrm{df}=6, \mathrm{p}<0.001\right)$. When each subject category was compared to each other using the Mann Whitney U Test, the sources of differences were determined for Engineering and Social Sciences $(\mathrm{U}=41585.500$, $\mathrm{Z}=-2.924, \mathrm{p}=0.003)$, Humanities and Medical Sciences $(\mathrm{U}=15,038.500, \mathrm{Z}=-3.276, \mathrm{p}=0.001)$, Humanities and Social Sciences $(\mathrm{U}=92,069.500, \mathrm{Z}=-2.192, \mathrm{p}=0.028)$, Medical Sciences and Natural Sciences $(U=17,338.500, Z=-2.627, p=0.009)$, Medical Sciences and Social Sciences $(\mathrm{U}=128,110.000, \quad \mathrm{Z}=-7.648, \mathrm{p}<0.001)$ and Natural Sciences and Social Sciences $(\mathrm{U}=96,527.000, \mathrm{Z}=-3.310, \mathrm{p}=0.001)$.

\section{A.3. Impact-factor journals citing blacklisted journals}

The fact that a journal has a valid impact factor or is included in citation indexes is used by policymakers and managers to determine the level of that journal. We analysed the relationship between the impact-factor journals and their citations to blacklisted journals. To be able to make accurate statistical analyses, the impact factor of all journals cited in blacklisted journals were gathered with yearly changes. For example, if two articles in the same journal cited the blacklisted journals in 2018 and 2019, JCR 2017 and JCR 2018 were used. As a result, 1,600 impact factors for 1,047 IF journals were obtained.

Before presenting the comparisons between impact factors and citations to blacklisted journals, it is worth mentioning those journals dropped from citation indexes. Twenty impact-factor journals that cited blacklisted journals 125 times were dropped from JCR or WoS for different reasons. Fifteen of them were dropped from the index without listing any unethical concerns. This means that coverage of the journals did not meet the WoS selection criteria (Clarivate, 2018). Scientific World Journal was suppressed from JCR based on citation stacking and four journals (Business Ethics: A European Review, Environmental Engineering and Management Journal, Eurasia Journal of Mathematics Science and Technology Education and Industria Textila) were dropped for their excessive self-citation rates. These five journals cited blacklisted journals 39 times. Furthermore, although they were not indexed in JCR and did not have an impact factor, 15 journals were excluded from ESCI after being indexed for a couple of years in ESCI. All these findings can be commented as questionable journals in WoS cited blacklisted journals; however, statistical tests did not confirm this comment.

The Spearman's Rho correlation coefficient shows that the correlation between journal impact factors and the number of citations to blacklisted journals is very low, at a $99 \%$ confidence level $(r=0.090, p<0.001)$. Also, according to the Kruskal-Wallis test results, the differences between journal impact-factor quartiles and the number of citations to blacklisted journals were not significant $\left(\chi^{2}=7.785, \mathrm{df}=3, \mathrm{p}=0.051\right)$. However, the Mann Whitney $\mathrm{U}$ test revealed that the only differences were found between Q1 and Q4 journals' number of citations to blacklisted journals $(U=72661.500, Z=-2.648, p=0.008)$.

The impact-factor range of blacklisted journal citers is from 0 to 27.604 (mean=1.689, median $=1.378, \mathrm{SD}=1.471,25 \%=0.745,75 \%=2.252$ ), while the minimum impact factor of the whole JCR between 2011 and 2018 is 0 and the maximum is 244.585 (mean=2.072, median $=1.373, \mathrm{SD}=3.310,25 \%=0.704,75 \%=2.462$ ).

Eighty percent of the journals in JCR cited blacklisted journals only one time, and there is a significant difference between the impact factors of one-time citers and the others 
$(U=174977.000, Z=-3.668, p<0.001)$. However, the surprising result is that the average impact factor of journals that cited blacklisted journals more than once is 1.896 (median=1.634), and this is higher than that of one time citers (mean=1.639, median=1.318).

Table 2 shows the main features of 10 impact-factor journals that cited blacklisted journals more than 20 times.

Table 2. Ten Impact-Factor Journals that Cited Blacklisted Journals more than 20 Times

\begin{tabular}{lccccc}
\hline \multicolumn{1}{c}{ Journal name } & IF & $\begin{array}{c}\text { Nof } \\
\text { articles } \\
\text { citing } \\
\text { blacklisted } \\
\text { journals }\end{array}$ & $\begin{array}{c}\text { Nof } \\
\text { citations to } \\
\text { blacklisted } \\
\text { journals }\end{array}$ & $\begin{array}{c}\text { Publisher } \\
\text { country }\end{array}$ & $\begin{array}{c}\text { Journal } \\
\text { self- } \\
\text { citation } \\
\text { rate of the } \\
\text { journal }\end{array}$ \\
\hline ACTA MEDICA MEDITERR & 0.249 & 25 & 126 & Italy & $63.7 \%$ \\
SUSTAINABILITY-BASEL & 2.576 & 56 & 56 & Switzerland & $38.9 \%$ \\
SAGE OPEN & 0.715 & 16 & 45 & USA & $2.8 \%$ \\
SYSTEM & 1.979 & 31 & 34 & England & $12.4 \%$ \\
FRONT PSYCHOL & 2.067 & 24 & 26 & Switzerland & $15.5 \%$ \\
EGIT BILIM & 0.493 & 19 & 25 & Turkey & $14.0 \%$ \\
PLOS ONE & 2.740 & 25 & 25 & USA & $5.1 \%$ \\
COMPUT EDUC & 5.296 & 21 & 22 & England & $11.6 \%$ \\
INT J BANK MARK & 2.800 & 11 & 21 & England & $33.7 \%$ \\
COMPUT HUM BEHAV & 5.003 & 20 & 21 & USA & $11.4 \%$ \\
\hline
\end{tabular}

All the test results on impact-factor journals prove that it is impossible to evaluate the blacklisted journals by looking at the impact factors or impact-factor percentiles of the journals because no pattern is identified. The impact factor is neither a descriptor of the quality of a paper nor the quality of citation. Therefore, it reveals the importance of content-based analysis in understanding the purpose of citations to blacklisted journals.

\section{PART B: Self-citation analyses}

We have analysed the countries of the corresponding authors of cited and citing papers. Table 3 presents the top 10 countries of cited and citing papers. Corresponding authors of papers published in blacklisted journals were most often from Turkey (335 papers), whereas citing papers were most often from the USA (555 papers). 
Table 3. Top 10 Countries of Cited and Citing Papers

\begin{tabular}{lclc}
\hline $\begin{array}{c}\text { Country of corresponding author } \\
\text { of cited papers }\end{array}$ & Number of papers & $\begin{array}{c}\text { Country of } \\
\text { corresponding author } \\
\text { of citing papers }\end{array}$ & $\begin{array}{c}\text { Number of } \\
\text { papers }\end{array}$ \\
\hline Turkey & 335 & USA & 555 \\
India & 259 & Turkey & 386 \\
Malaysia & 226 & Malaysia & 368 \\
Iran & 174 & China & 291 \\
Nigeria & 160 & India & 288 \\
China & 142 & Spain & 268 \\
USA & 136 & Iran & 257 \\
Pakistan & 120 & Indonesia & 188 \\
Saudi Arabia & 120 & South Africa & 184 \\
Taiwan & 117 & Australia & 172 \\
\hline
\end{tabular}

We have calculated pairs of the most-often citing countries using the affiliation of corresponding authors. Figure 4 presents the top 50 pairs.

Figure 4. Top 50 Pairs of Countries of Corresponding Authors of Cited and Citing Papers

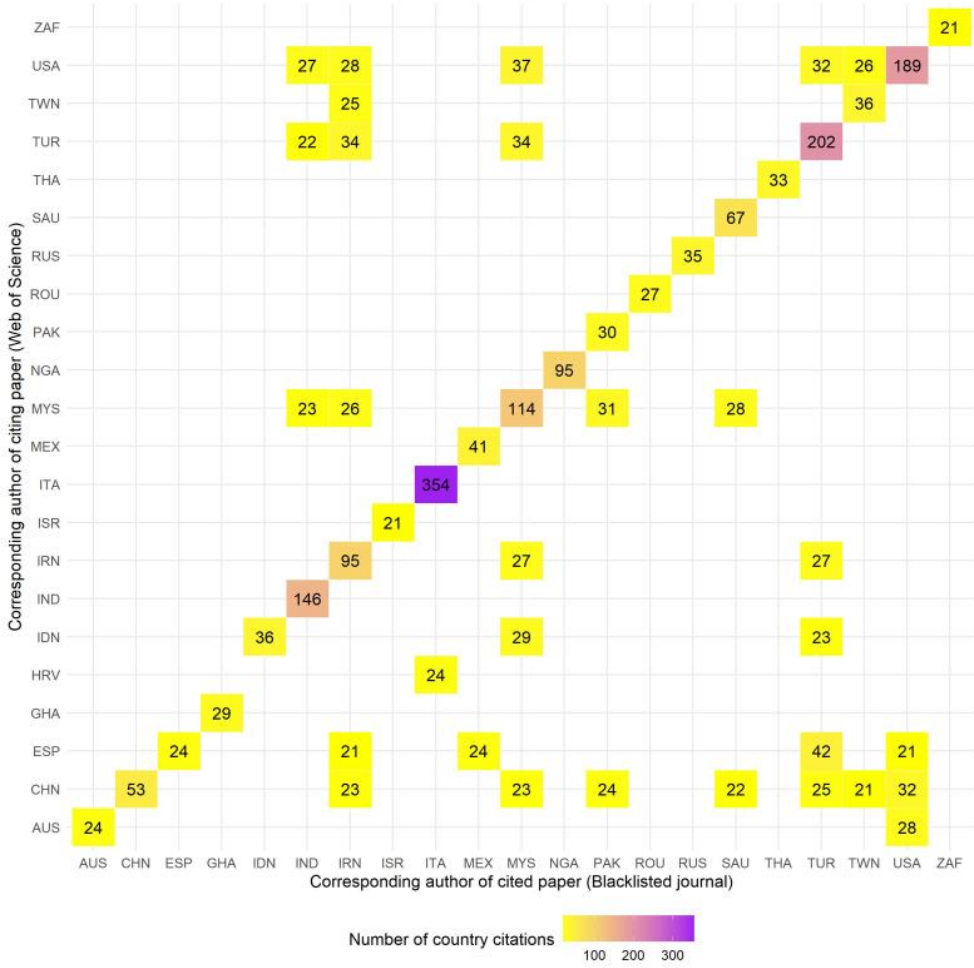

Italian researchers published the highest number of papers in WoS journals, which cited papers authored by Italian researchers in blacklisted journals. This result is not expected because previous studies have shown that Italian researchers did not publish intensively in blacklisted journals. Thus, we also conducted an author-level analysis of self-citations, which revealed that Italian researchers cited multiple blacklisted papers, of which they were co-authors. 
In the analysis of self-citation on the author level, we have considered all the authors (not only the corresponding ones). By the analysis of bibliographical data and PDF files of the paper, we have found that $641(9.5 \%)$ of 6,750 are self-citations from $369 \mathrm{WoS}$ journals to 53 blacklisted journals. The highest number of author self-citations from one WoS journal is 65 (all citations to one blacklisted journal; the corresponding authors of 55 from 65 of those WoS journal papers are affiliated in Italy). The highest number of author self-citations of blacklisted papers from one journal is 147 .

Table 4 presents the top 10 self-citing authors from our sample. In total, we found 641 authors who self-cited their blacklisted papers.

Table 4. Top 10 of Self-Citing Authors

\begin{tabular}{lccc}
\hline Country affiliation of the author & $\begin{array}{c}\text { Number of } \\
\text { self-citations }\end{array}$ & $\begin{array}{c}\text { Number of } \\
\text { unique } \\
\text { blacklisted } \\
\text { papers }\end{array}$ & $\begin{array}{c}\text { Number of } \\
\text { unique WoS } \\
\text { papers }\end{array}$ \\
\hline Italy & 41 & 12 & 9 \\
Italy & 26 & 6 & 5 \\
Croatia & 21 & 17 & 7 \\
Italy & 18 & 6 & 3 \\
Israel & 17 & 10 & 2 \\
Italy & 16 & 12 & 4 \\
Italy & 16 & 7 & 4 \\
The Netherlands & 8 & 8 & 1 \\
Italy & 8 & 5 & 3 \\
Italy & 7 & 5 & 5 \\
India & 7 & 7 & 1 \\
\hline
\end{tabular}

\section{Discussion and Conclusions}

The main aim of our study is to reveal the contributions of citation indexes, which are accepted as the authority in research evaluations, to the visibility of blacklisted journals whose scientific levels are always considered quite low in academia. According to the results, $13 \%$ of the blacklisted articles were cited by WoS journals and 37\% of the citations came from the impactfactor journals. If we accept being cited from authority citation indexes as a tool for visibility, it is obvious that the indexes help the blacklisted journals to be visible regardless of the name of the index, SSCI, A\&HCI or ESCI. The question to be asked at this point is: Do citations to the blacklisted journals make citation indexes questionable, or do these citations require a closer look at articles published in blacklisted journals? It is easy to accept all the papers published in blacklisted or questionable journals as low-quality, but without answering the question, it is difficult to draw a boundary for the definition between high and low quality.

The findings show that there are no significant differences between the impact factors and the number of citations to the blacklisted journals. The high-impact-factor journals, especially open access mega journals, can cite blacklisted journals, so it is important to understand the reasons 
behind this. All the statistical tests conducted using journal-level statistics in our study confirm the emerging need to analyse the citations to blacklisted journals at the article level.

Why do authors cite others? has been the main question of citation-analysis studies in the literature since the beginning, but our question is Why do authors cite blacklisted journals? after revealing the contributions of citation indexes to the visibilities of blacklisted journals. Some interesting patterns were found, including author, journal or country self-citations; however, they are not enough to understand the whole picture. The second part of our project to understand citation contexts will help us answer this question.

This is the first study in which a large-scale analysis of citations to predatory journals is conducted using WoS. When compared to the different results present in the citation studies based on Scopus, it is difficult to assess differences in terms of citing predatory journals in these two databases. Taking into account that only $13 \%$ of articles in our study are cited, we can be sure that citations to predatory journals are much more frequent in Google Scholar because it was reported that $43 \%$ of articles analyzed in were cited (Björk et al., 2020). However, as an academic search engine, Google Scholar indexes all types of academic materials without any selection criteria as distinct from WoS or Scopus. Therefore, the difference in the number of citations is expected.

Since we did not assess the quality of cited papers published in blacklisted journals, there are two possible interpretations of the main result of our study: 1) up to $13 \%$ of worthless articles in predatory journals can still leak to the mainstream literature legitimised by WoS, and 2) up to $13 \%$ of papers published in blacklisted journals are somehow important for developing a scholarly legitimate discussion in social science. Unlike Oermann et al. (2020), we are not so sure that the important conclusion of the studies on predatory journals is to completely stop citing. Further, we prefer to leave the question raised by the result of our study open.

By pointing out that most of the citers are from the USA, our study supports results by Oermann et al. (2019) and differs from the conclusion presented by Frandsen (2017). Both Oermann et al. and Frandsen used Scopus for their analysis, so the difference is most likely caused by the fact that Frandsen was using a version of Beall's list from 2014 and Oermann et al. (just like us) used the last available version of the list from 2017. However, it is also important to note that the study by Frandsen did not filter journals according to their discipline; the study by Oermann et al. was focussed on nursing journals, and our study focussed on journals from the social sciences.

One could assume that papers in predatory journals by authors from some countries will more likely be cited in WoS than others. In general, our results seem to indicate that such an assumption is false. When it comes to being cited, the affiliation of the author of the article from the predatory journal does not seem to play such a significant role. The countries from which the authors produced most of the cited papers are also the countries that produce most of the predatory journals (Demir, 2018b). It is not so surprising that US authors cited a relatively high share of papers published in predatory journals because the USA has much more publications in WoS than Turkey or India (Schlegel, 2015).

However, it is quite interesting that scholars from the USA cited predatory journals 555 times and scholars from China did so 291 times, even though their yearly output of articles in WoS is similar. This could indicate that when publishing their papers, it is relatively easy for US scholars to distinguish journals deemed as predatory; they are less aware of the predatory nature 
of journals when it comes to citing. It could also be interpreted that for some US scholars, many predatory journals are less prestigious places to publish, but they can still be sources of legitimate knowledge. However, to better understand this phenomenon, content-based analysis of the citations to predatory journals would be required.

Our results also support a conclusion made by Oermann et al. (2019), who pointed out that there is no significant difference between journals with and without JIF in terms of citing predatory journals. Our results indicate that there is no connection between the value of the JIF of a given journal and this journal's citations to predatory journals. Although the number of such citations is relatively small, this could be another argument against treating JIF as a measure of journals' quality.

\section{Appendix}

The list of 65 analysed blacklisted journals is available here:

https://figshare.com/articles/dataset/Appendix_-_List_of_65_blacklisted_journals/13560326

\section{References}

Anderson, R. (2017, July). Cabell's New Predatory Journal Blacklist: A Review. Scholarly Kitchen. https://scholarlykitchen.sspnet.org/2017/07/25/cabells-new-predatory-journalblacklistreview/?utm_source=feedburner\&utm_medium $=$ email\&utm_campaign $=$ Feed $\% 3 \mathrm{~A}+\mathrm{Sch}$ olarlyKitchen+\%28The+Scholarly+Kitchen\%29

Anderson, R. (2019). Citation Contamination: References to Predatory Journals in the Legitimate Scientific Literature-The Scholarly Kitchen. Scholarly Kitchen. https://scholarlykitchen.sspnet.org/2019/10/28/citation-contamination-references-topredatory-journals-in-the-legitimate-scientific-literature/

Beall, J. (2013). The Open-Access Movement is Not Really about Open Access. TripleC, $11(2), 589-597$.

Bivens-Tatum, W. (2014). Reactionary Rhetoric Against Open Access Publishing. TripleC, 12(2), 441-446. https://doi.org/10.31269/triplec.v12i2.617

Björk, B.-C., Kanto-Karvonen, S., \& Harviainen, J. T. (2020). How Frequently Are Articles in Predatory Open Access Journals Cited. Publications, 8(2), 17. https://doi.org/10.3390/publications8020017

Bohannon, J. (2013). Who's Afraid of Peer Review? Science, 342(6154), 60-65. https://doi.org/10.1126/science.342.6154.60

Cabells. (2021). Get a quote. https://www2.cabells.com/get-quote

Cano, V. (1989). Citation behavior: Classification, utility, and location. Journal of the American Society for Information Science, 40(4), 284-290.

Clarivate. (2018, June 27). Web of Science: Editorial statement about dropped journals. https://support.clarivate.com/ScientificandAcademicResearch/s/article/Web-of-ScienceEditorial-statement-about-dropped-journals?language=en_US

Clarivate Analytics. (2012). OECD Category Scheme. http://help.prodincites.com/inCites2Live/filterValuesGroup/researchAreaSchema/oecdCategoryScheme .html

Cobey, K. D., Lalu, M. M., Skidmore, B., Ahmadzai, N., Grudniewicz, A., \& Moher, D. (2018). What is a predatory journal? A scoping review [version 1; referees: 2 approved, 1 not approved]. F1000Research, 7, 1001. 
https://doi.org/10.12688/f1000research.15256.1

Demir, S. B. (2018a). Scholarly databases under scrutiny. Journal of Librarianship and Information Science, 096100061878415. https://doi.org/10.1177/0961000618784159

Demir, S. B. (2018b). Predatory journals: Who publishes in them and why? Journal of Informetrics, 12(4), 1296-1311. https://doi.org/10.1016/j.joi.2018.10.008

Else, H. (2019). Impact factors are still widely used in academic evaluations. Nature, d41586019-01151-01154. https://doi.org/10.1038/d41586-019-01151-4

Ezinwa Nwagwu, W., \& Ojemeni, O. (2015). Penetration of Nigerian predatory biomedical open access journals 2007-2012: A bibiliometric study. Learned Publishing, 28(1), 23 34. https://doi.org/10.1087/20150105

Frandsen, T. F. (2017). Are predatory journals undermining the credibility of science? A bibliometric analysis of citers. Scientometrics, 113(3), 1513-1528. https://doi.org/10.1007/s11192-017-2520-x

González-Sala, F., Osca-Lluch, J., \& Haba-Osca, J. (2019). Are journal and author selfcitations a visibility strategy? Scientometrics, 119(3), 1345-1364. https://doi.org/10.1007/s11192-019-03101-3

Houghton, F. (2017). Ethics in academic publishing: A timely reminder. Journal of the Medical Library Association, 105(3), 282-284. https://doi.org/10.5195/JMLA.2017.122

Krawczyk, F., \& Kulczycki, E. (2020). How is open access accused of being predatory? The impact of Beall's lists of predatory journals on academic publishing. The Journal of Academic Librarianship, 102271. https://doi.org/10.1016/j.acalib.2020.102271

Leydesdorff, L., Bornmann, L., Comins, J. A., \& Milojević, S. (2016). Citations: Indicators of Quality? The Impact Fallacy. Frontiers in Research Metrics and Analytics, 1. https://doi.org/10.3389/frma.2016.00001

Moussa, S. (2020). Citation contagion: A citation analysis of selected predatory marketing journals. Scientometrics. https://doi.org/10.1007/s11192-020-03729-6

Norman, E. R. (2012). Maximizing Journal Article Citation Online: Readers, Robots, and Research Visibility. Politics \& Policy, 40(1). https://doi.org/10.1111/j.17471346.2011.00342.x

Norman, E. R. (2013). Maximizing research visibility, impact, and citation: Tips for editors and authors. In Science Editors' Handbook (2nd ed., pp. 224-227). European Association of Science Editors.

Oermann, M. H., Nicoll, L. H., Ashton, K. S., Edie, A. H., Amarasekara, S., Chinn, P. L., Carter-Templeton, H., \& Ledbetter, L. S. (2020). Analysis of Citation Patterns and Impact of Predatory Sources in the Nursing Literature. Journal of Nursing Scholarship, 52(3), 311-319. https://doi.org/10.1111/jnu.12557

Oermann, M. H., Nicoll, L. H., Carter-Templeton, H., Woodward, A., Kidayi, P. L., Neal, L. B., Edie, A. H., Ashton, K. S., Chinn, P. L., \& Amarasekara, S. (2019). Citations of articles in predatory nursing journals. Nursing Outlook, 67(6), 664-670. https://doi.org/10.1016/j.outlook.2019.05.001

Olivarez, J., Bales, S., Sare, L., \& vanDuinkerken, W. (2018). Format Aside: Applying Beall's Criteria to Assess the Predatory Nature of both OA and Non-OA Library and Information Science Journals. College \& Research Libraries, 79(1), 52-67. https://doi.org/10.5860/crl.79.1.52

Oppenheim, C. (1996). Do citations count? Citation indexing and the Research Assessment Exercise (RAE). Serials, 9(2), 155-161.

Organisation for Economic Co-Operation and Development. (2007). Revised field of science and technology (FOS) classification in the frascati manual DSTI/EAS/STP/NESTI(2006)19/FINAL. http://www.oecd.org/science/inno/38235147.pdf 
Schlegel, F. (Ed.). (2015). UNESCO science report: Towards 2030. UNESCO Publ.

Shen, C., \& Björk, B.-C. (2015). 'Predatory' open access: A longitudinal study of article volumes and market characteristics. BMC Medicine, 13(1), 230-230. https://doi.org/10.1186/s12916-015-0469-2

Siler, K. (2020). Demarcating spectrums of predatory publishing: Economic and institutional sources of academic legitimacy. Journal of the Association for Information Science and Technology, 71(11), 1386-1401. https://doi.org/10.1002/asi.24339

Simkin, M., \& Roychowdhury, V. (2015). Do you sincerely want to be cited? Or: Read before you cite. In B. Cronin \& C. R. Sugimoto (Eds.), Scholarly Metrics Under the Microscope: From Citation Analysis to Academic Auditing (pp. 203-210). Information Today. https://doi.org/10.1111/j.1740-9713.2006.00202.x

Somoza-Fernández, M., Rodríguez-Gairín, J.-M., \& Urbano, C. (2016). Presence of alleged predatory journals in bibliographic databases: Analysis of Beall's list. El Profesional de La Información, 25(5), 730. https://doi.org/10.3145/epi.2016.sep.03

Sorokowski, P., Kulczycki, E., Sorokowska, A., \& Pisanski, K. (2017). Predatory journals recruit fake editor. Nature, 543(7646), 481-483. https://doi.org/10.1038/543481a

Stöckelová, T., \& Vostal, F. (2017). Academic stratospheres-cum-underworlds: When highs and lows of publication cultures meet. Aslib Journal of Information Management, 69(5), 516-528. https://doi.org/10.1108/AJIM-01-2017-0013

Taşkın, Z., \& Al, U. (2018). A content-based citation analysis study based on text categorization. Scientometrics, 114(1), 335-357. https://doi.org/10.1007/s11192-0172560-2 